\title{
On the Organization Forms and Structures of Local Government in European Countries
}

\author{
Dr. Teki Kurti \\ Part-Time Lecturer at the University of Tirana, Faculty of History and Philology; \\ Dean of the Faculty of Political Sciences and Vice Rector of Vitrina University
}

\section{Doi:10.5901/ajis.2013.v2n8p550}

\section{Abstract}

The territorial organization of governing in the "unitary state", "federal state", "confederation", with their constituent units is another aspect of the functioning of governing, which shows the government allocation. The above mentioned types are distinguished by the governing ratio in the territorial integrity of the nation-state, which in the governing system of liberal democracy are known as "central governing" and "local governing" followed by the attributes of "centralization", "decentralization", "self-governing" or "local autonomy". It observes the basic functioning of the system, the creation and realization of the relations between the government and the governed, through which are implemented the basic principles of: participation in governance; -expression of the will and liking of governing; - fulfilment of tasks of governing according to the interests and aspirations of the governed; - responsibility and accountability of the government. The effectiveness of the government, assessed through the fulfilment of tasks with concrete results related to the fulfilment of the interests of the entire nation and society, is another important aspect in the system of governing.

Keywords: Local governing, regions, departments, municipalities, decentralization, centralization, central governing, Unitarian states, federal state, self-governing

Liberal democracy made more than evident the relation between "central government" and "local government", "centralization" and "decentralization", because it was put under the function of its essence, which is expressed in terms of "governing by people" and of "governing for people".

Local governing represents the first election school in the formation of the bodies and institutions that are closer to the governed, that in it carry the greatest and aware interest of the governed.

Local governing is thought to be a realization of the political procedures which contain the direct fulfilment of the needs and wants of the governed. Therefore we are talking about political procedures (such as laws, decrees, decisions, orders) which meet even the direct interests of the governed.

What can we say about the general features of the structure of local governing? Almost in every European country (member countries of the European Union until 2005) there are more than one levels of local governing; most of them have two levels, some have three1. According to their alignment in the escalation of the central governing levels can be illustrated graphically in the shape of a pyramid. (See the example of France). The lower unit (the smallest one in size) is the commune or municipality - in terms of communities that appear as the basic authority of the last level.

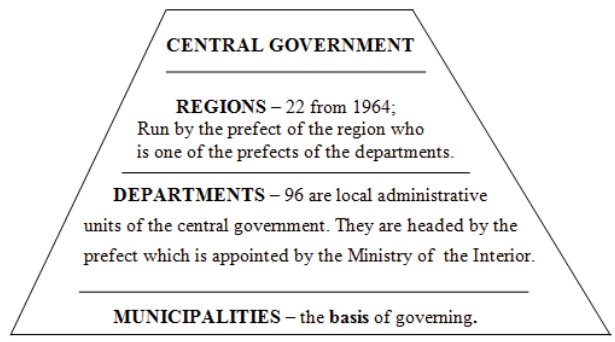

${ }^{1}$ Representative Government in Modern Europe, Third Edition, Michael Gallagher, p. 162. 
Also, almost in every European country exists at least one additional or intermediate link (unit) of the local government, which is between the municipality or community on the one side, as a basic unit of governing and the central government on the other side.

They are characterized by the names counties (province), departments. In Denmark there are 14, in Netherlands 12, in Italy around 90 provinces. France has more than 90 departments. Meanwhile there exists another additional level that is of the region which is "on top of central governing", there are 15 of this category in Italy and 17 in Spain. Among others, regions express the territorial distribution of power based on the definition of "unitary state" or "federal state". Whilst in Netherlands the authority if this region is very weak, Germany is an exception. Being a "federal state", the municipal governing system is under the jurisdiction of Lander governments. Under the Landers there are two local governing levels: the kreise which are one level above and the municipalities which are one level below.

The structures of the organization of local governing in the European member states originate from two models that characterize the relationship between central governing and local governing. Those are the Dual model (binary) and the homogeneous model (united). ${ }^{2}$

In the dual model, local governing has the status of free position for to decide on the basis of local conditions regarding organisational structures, and staff. The staffs are organized in a horizontal dimension, connecting one local body with another. The structures of local governing are not considered as part of a single structure of the state. However, sovereignty is embodied by the central government. An example of this model was the governing of Britain, but the model changed during the 1980s and 1990s, when the country was governed by the Conservative Party.

In the homogeneous model, the authority of the central power and local power is united in specific governing structures such as that of the prefecture. It is an organization appointed by the central government, which supervises the administration of specific communities and is responsible to the Ministry of the Interior.

The level of the prefectures is in the vertical extents, part of the unitary hierarchy that starts from the central governing and ends at the local governing. A typical example of this model has been France. For the more, in France, national rank politicians are mayors in their cities. They tend to defend the local interests at the central institutions. The organization of local government has always been part of the changes process. ${ }^{3}$

The tendency towards the limitation of the number of units is a general trend. This is intended to avoid weaknesses in the implementation of policies when the levels of the local governing are limited in their scope, have a small number of population and insufficient natural resources and capital.

Thus, for example, in 1952, Sweden had 2500 municipalities, whilst in 1969 their number was limited to 278. The increment of the sizes limited the number of "the free rider"- people who exploit the resources of the municipality but do not pay for them. ${ }^{4}$

In the table below is shown the average population in the lowest levels of the elected local authority. ${ }^{5}$

\begin{tabular}{|lc|}
\hline $\begin{array}{l}\text { Country } \\
\text { (1991) }\end{array}$ & Average Population \\
\hline England & 127.000 \\
Scotland & 91.620 \\
Ireland & 41.910 \\
Sweden & 30.000 \\
Netherlands & 17.860 \\
Belgium & 16.740 \\
Finland & 10.646 \\
Norway & 9.145 \\
Germany & 7.240 \\
Italy & 6.800 \\
Spain & 4.700 \\
France & 1.500 \\
\hline
\end{tabular}

It has been aimed that the "lowest levels" of local governing be considered as "more important" than the "higher levels" of

\footnotetext{
2 Political science, Robert L. Cord, 1985, p. 176

${ }^{3}$ Introduction to Politics, Veruan Van Dyke, p. 166.

${ }^{4}$ Michael Gallagher, p. 179

5 Ibid. p. 181.
} 
this governing. This was associated with the increased public functions for which they are responsible.

Relations between levels are not of a too hierarchical nature, in the sense that one level reports to the other level. The tendency of sharing work between the levels of local governing, which is defined in the constitution or in the national legislation, is the one that operates the most. Mid-level bodies are more responsible for strategic planning and coordination, whilst those of lower levels are directly connected with the realization of basic services. The evaluation of each of the levels of local governing is related to the importance of the functions that each of them has and the degree of autonomy that they must meet.

Almost in all developed European countries, local governing structures originated from their historical past, even from pre-modern historical periods. $(1815)^{6}$

The second half of the twentieth century was a turning point for local governing, when the foundations for the modern European local governing system were laid. This was followed by many organizations and reorganizations. Spencer and Wallin are among the most well-known researchers of the European local government in the process of historical development. ${ }^{7}$ Spencer notes that for historians "it is not exceptional to seek traces of the development of the municipality in an almost ceaseless process which has started in the twelfth century and has continued until nowadays". ${ }^{8}$ He also emphasizes that the current system of municipalities in Italy has been put arbitrary by Napoleon Bonaparte (1802) and the general structures of local governing in Italy coincide with the unification of Italy in 1861.

The current system of local governing in Britain has followed the steps of the very old system, which with the major reformations that were made to it after 1835, is based on the low level district administrations and on the high level of county administration. In Ireland, today's division in counties as a basic unit of the local administration began with the Roman conquest and was completed more or less in the end of the seventeenth century. Municipalities in France date in the Napoleonic Era. The Swedish local governing was established in 1836 with the creation of the municipalities based for hundreds of years on administrative units. The local government in Germany has historic traditions, the origin of which is in the numerous rights that medieval towns had. This tradition was interrupted by the Third Reich that put the centralized totalitarian system of governing, but immediately after the Second World War was realized the organization of today's municipality - Gemeinde.

\section{Degree Of Autonomy, Content And Realization Ways}

The increment of problems from the perspective of participation in governing through the spaces where imputes initiatives are undertaken, as well as the spaces where outputs are formulated and realized, means special mechanisms of the activities and relations between central governing bodies and local governing bodies. Through such mechanisms it is aimed to realize the governing as a whole, as well as the particularities related to the space of the local governing expressed through "decentralization" and "autonomy" of local governing.

First of all, it is the administrative structural mechanisms of the central government that operate locally. Such mechanisms are:

Agencies (or institutions) of central government that are organized locally and that are directly responsible for the administration of policies before the central bureaucracy. Thus, for example, in Italy, locally, until the reforms of mid 1970s, there operated 70,000 agencies of the central government.

Local Bodies (institutions) that act on behalf of the central government and of the implementation of the outputs of the central administration. It is quite common that the central government mandate the local government to administrate specific policies on its behalf.

The totality of the governing system makes it unavoidable for the above mechanisms of central governing to act alongside those of local governing. This is the reason that for the local governing bodies to operate as governing bodies being closer to the governed and more direct in the fulfilment of the imputes, it is raised the issue of their powers that in the liberal democratic system are summarized in the so-called decentralization with the pre-condition of the autonomy of local governing.

The authors of the study "Representative Government in Modern Europe" wrote that " it is vital to determine the area within which the local government's bureaucracy is committed to fully implement the national policy and as many

\footnotetext{
${ }^{6}$ L. Cord, op. cit., p. 337.

${ }^{7}$ Local Government in Liberal Democracies, p. 76.

${ }^{8}$ Gallagher, op. cit., p. 162
} 
areas in which the local government bodies are free to modify national policies upon their own initiative". 9

The determination of the local bodies is done in two directions:

1- The power of the local government to take decisions without being contested from the central authorities.

2- The degree of independence for the provision of financial support, including the management of the revenue and making expenses. The de facto degree of autonomy of every local government is determined from the opportunities of raising and spending funds independently.

The decentralization in the European countries is realized through an uninterrupted process of continuity. It was conditioned by a number of factors:

- The historical process of formation of nation states and of the institutionalization of governing bodies of liberal democracy;

- The nature of the political culture of the elite and of the mass of population.

- The undertaking of constitutional changes from certain political forces.

- The need of optimizing governing in accordance with the influence of the new factors of the computing revolution, integration and globalization.

Constitutions have been crucial for the functioning of local bodies.

Constitutions mandate different forms of self-governing. In the constitutional document "The Instrument of Government" of Sweden is sanctioned that "the Swedish democracy is based on the freedom of thought, in the general and equal elections and that it is realized through the representative and parliamentary bodies, as well as through selfgoverning". 10

Other constitutions define the "general powers" that local authorities should have. "General Powers" are connected to the local governing authorities in order to make regulations in any issue related to the territory of the exercise of this governing. These regulations are made in accordance with the national law. Basic Law (the Constitution) of the German Federal Republic for example guarantees to the gemeinde "the right to regulate, under its responsibility and within the limits of law, the entire issues of the local community". ${ }^{11}$

Such expressions are part of European doctrine of subsidization-the essence of which is the idea that issues must be handled as much as possible at local levels. Such a doctrine is specifically supported by Christian democracy.

However the policies of the European unitary states are present in the tendencies of centralizing the central government, without clearly defining the powers of local authorities. This allowed national governments to be more involved in local governing. On the contrary, the organization of the constitution of federal states made it difficult, if not impossible for the "the government of the day" to make changes.

Very good examples of the derogatory treatment of the local governing system by the national government, with the aim of politicizing the local government bodies, are found in Britain, Ireland. ${ }^{12}$

Britain is known for the local government authority. This happened because the British, for ages have highly valued local autonomy and the values that they had regarding their autonomy are part of the political culture.

All the counties and boroughs (cities) were entitled to the right to elect councils with permanent committees for each field of administration. Their powers included the control of police, education, health, welfare issues, housing, and transport. It had been very difficult for the Parliament to ignore local officials. Usually it has intervened in cases of emergency situations. ${ }^{13}$

However, Britain is also recognized for the efforts of the party governments for the politicization of local governing in terms of policy from "government of the day", especially for to take the functions of local authorities.

\footnotetext{
${ }^{9}$ Gallagher, op. cit., p. 153

${ }^{10}$ L. Cord, op. cit., p. 182

${ }^{11}$ L. Cord, op. cit., p. 182

12 Gallagher, op. cit., p. 162

13 Ibid. p. 162
} 